\title{
The pituitary-adrenal axis in idiopathic retinal vasculitis
}

\author{
H E Palmer, M R Stanford, C Lowy, M J Wheeler, G R Wallace, E M Graham
}

\begin{abstract}
Aims-To determine whether patients with idiopathic retinal vasculitis have altered production of cortisol and dehydroepiandrosterone sulphate (DHEA-S), and whether differences in these variables occur between those who are sensitive (SS) and resistant (SR) to steroids.

Methods-20 patients with retinal vasculitis (off treatment) and 10 control subjects were prospectively recruited. Morning cortisol and DHEA-S levels were measured, and cortisol secretion rates and short synacthen tests (SST) carried out in patients before treatment, when on prednisolone $20 \mathrm{mg} / \mathrm{day}$, and in controls.

Results-There were no differences in any variables between patients and controls. For retinal vasculitis patients pretreatment, the SST was lower in SR patients $(p=0.02)$. More of the $S R$ patients had ischaemic retinal vasculitis $(p<0.001)$.

Conclusions-Cortisol and DHEA-S are not involved in the pathogenesis of retinal vasculitis. $S R$ in retinal vasculitis may be associated with a defective hypothalamicpituitary-adrenal axis.

(Br f Ophthalmol 1999;83:1393-1395)
\end{abstract}

Idiopathic retinal vasculitis is a potentially blinding inflammatory disease ${ }^{1}$ for which first line treatment with systemic corticosteroids is indicated. ${ }^{2}$ Some patients require second line immunosuppressants in addition to steroids. ${ }^{3}$ If it were possible to identify steroid resistant patients with retinal vasculitis, then more effective treatment protocols could be planned from the outset.

The hypothalamic-pituitary-adrenal (HPA) axis refers to the communication between the hypothalamus, anterior pituitary, and adrenal gland resulting in the controlled secretion of adrenocortical hormones. There is evidence that autoimmune diseases arise where this axis is defective. ${ }^{4-6}$ Retinal vasculitis is considered to be initiated by autoreactive antiretinal $\mathrm{T}$ helper 1 (Th1) cells. ${ }^{7-9}$ The adrenocortical hormone cortisol leads to a predominantly $\mathrm{T}$ helper 2 cellular response, ${ }^{10}{ }^{11}$ while dehydroepiandrosterone (DHEA) opposes cortisol's immune regulation, by favouring a Th1 environment. ${ }^{12} 13$

We hypothesised that retinal vasculitis patients would have constitutively lower cortisol production but higher levels of DHEA-S than healthy controls. Additionally, we postulated that, among the retinal vasculitis patients themselves, those who show a good clinical response to exogenous steroid (steroid sensi- tive group) would have lower cortisol production than those in whom outcome was poor (steroid resistant). Furthermore, we hypothesised that steroid resistance was related to higher levels of DHEA-S, which may antagonise the immune regulating effects of prednisolone.

\section{Methods}

PATIENT CHARACTERISTICS

Twenty patients with sight threatening idiopathic retinal vasculitis who were off treatment were prospectively and consecutively recruited from the medical eye unit, as were 10 healthy controls. Previous ethics committee approval had been granted and consent was obtained from each subject.

Those with evidence of an underlying systemic disease were excluded on the basis of history, systemic examination, and routine investigations: FBC, ESR, U+Es, glucose, LFTs, and serum ACE, chest $x$ ray, and Mantoux test. Those who had been on systemic steroid treatment in the past 2 years were excluded. Patients were categorised into ischaemic or non-ischaemic retinal vasculitis groups by fluorescein angiography: ischaemic retinal vasculitis occurring when peripheral retinal capillary non-perfusion was evident.

A patient was defined as being steroid resistant (SR) if that individual had a first relapse ${ }^{14}$ or failed to show a reduction in vitreous cellularity on $\geqslant 20 \mathrm{mg} /$ day prednisolone. Patients outside these criteria were classified as steroid sensitive (SS).

ADRENOCORTICAL TESTING

All the patients were admitted 24 hours before these specialist investigations. Morning (0800) blood was taken for cortisol, DHEA-S, and cortisol binding globulin (CBG) levels and a cortisol secretion rate (CSR) test was performed. The following morning (0800) a short synacthen test (SST) was done.

Prednisolone clearance analysis was performed on commencement of our standard oral prednisolone regimen. ${ }^{3}$

All tests, apart from the prednisolone clearance were repeated on 14 retinal vasculitis patients when they were on prednisolone 20 mg/day; 19 of the patients had blood prednisolone levels measured when on $20 \mathrm{mg} /$ day.

Controls had morning blood samples taken for cortisol, DHEA-S, and CBG, in addition to a CSR test and SST.

LABORATORY METHODS

Serum cortisol was determined by commercial competition ELISA (Enzymun-Test, Boehringer Mannheim Immunodiagnostics, 
Table 1 Subject characteristics, retinal vasculitis (RV) form, and adrenocortical variables before starting prednisolone

\begin{tabular}{|c|c|c|c|c|c|c|}
\hline & $\begin{array}{l}R V \\
\text { patients } \\
\text { (all) }\end{array}$ & Controls & $\begin{array}{l}p \text { Value } \\
\text { (RVv } \\
\text { controls) }\end{array}$ & $\begin{array}{l}R V S S \\
\text { patients }\end{array}$ & $\begin{array}{l}R V S R \\
\text { patients }\end{array}$ & $\begin{array}{l}p \text { Value } \\
(S S v S R)\end{array}$ \\
\hline Number & 20 & 10 & & 12 & 8 & \\
\hline Age (medians) & 34 & 38 & $1.00^{\star}$ & 39 & 32 & $0.70^{\star}$ \\
\hline \multicolumn{7}{|l|}{$\operatorname{Sex}(n):$} \\
\hline Male & 13 & 4 & $0.26 \dagger$ & 7 & 6 & $0.64 \dagger$ \\
\hline Female & 7 & 6 & & 5 & 2 & \\
\hline \multicolumn{7}{|l|}{$\mathrm{RV}$ form $(\mathrm{n})$ : } \\
\hline Ischaemic & 8 & & & 3 & 5 & $<0.001 \dagger$ \\
\hline Non-ischaemic & 12 & & & 12 & 0 & \\
\hline \multicolumn{7}{|c|}{ Adrenocortical variables (medians) } \\
\hline Cortisol (nmol/l) & 444.50 & 352.0 & $0.13^{\star}$ & 362.50 & 501.00 & $0.19^{\star}$ \\
\hline $\mathrm{CBG}(\mu \mathrm{g} / \mathrm{ml})$ & 49.05 & 48.25 & $0.96^{\star}$ & 45.40 & 50.70 & $0.40^{\star}$ \\
\hline Free cortisol $(\mathrm{nmol} / \mathrm{l})$ & 65.26 & 37.21 & $0.12^{\star}$ & 42.28 & 73.27 & $0.32^{\star}$ \\
\hline CSR ( $\mu \mathrm{mol} / 24$ hours) & 52.10 & 42.30 & $0.12^{\star}$ & 53.15 & 50.85 & $0.97^{\star}$ \\
\hline Cortisol rise on SST (nmo/l) & 272.00 & 310.00 & $0.46^{\star}$ & 352.00 & 203.00 & $0.02^{\star}$ \\
\hline DHEA-S $(\mu \mathrm{mol} / \mathrm{l})$ & 4.45 & 4.90 & $0.79^{\star}$ & 4.00 & 4.65 & $0.97^{\star}$ \\
\hline $\begin{array}{l}\text { Prednisolone clearance } \mathrm{ng} / \mathrm{ml} \\
\text { (mean (SD)) }\end{array}$ & $\begin{array}{l}126.80 \\
(75.90)\end{array}$ & & & $\begin{array}{l}121.10 \\
(81.70)\end{array}$ & $\begin{array}{l}139.60 \\
(70.20)\end{array}$ & $0.95 \dagger$ \\
\hline
\end{tabular}

^Denotes analysis with Mann-Whitney U; twith Fisher's exact test.

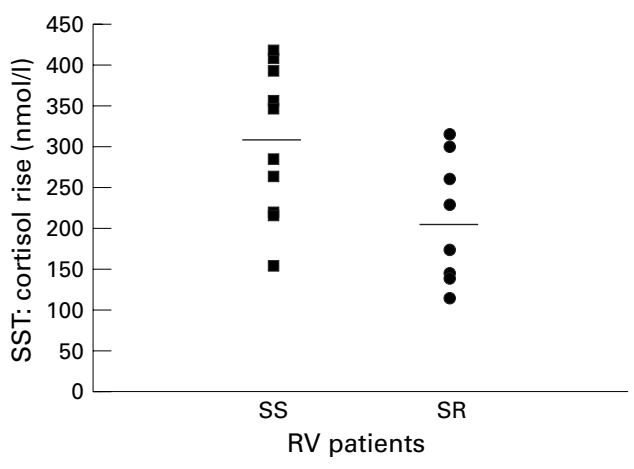

Figure 1 Difference in cortisol rise on the short synacthen test between steroid sensitive (SS) and steroid resistant (SR) retinal vasculitis patients before they commenced steroid treatment.

Germany). CBG levels were measured by radioimmunoassay (CBG-RIA-100, Medgenix Diagnostics, Belgium). DHEA-S and plasma prednisolone levels were determined using in-house radioimmunoassay techniques. Cortisol secretion rates were measured by a standard isotope dilution method. ${ }^{15}$

STATISTICAL ANALYSIS

Differences in levels between subject groups were measured by Mann-Whitney $U$ and Fisher's exact tests.

\section{Results}

PRETREATMENT CHARACTERISTICS AND ADRENOCORTICAL VARIABLES (TABLE 1)

There were no statistically significant differences in age or sex between any of the subject groups.

Significantly more of the SR patients had the ischaemic form of retinal vasculitis: five out of eight of the SR patients compared with none of the SS patients (Fisher's exact test, $\mathrm{p}<0.001$ ).

There were no significant differences in any of the steroid variables tested between the retinal vasculitis patients and controls. For the retinal vasculitis patients, the cortisol rise on SST was significantly lower in the SR group (Mann-Whitney U, p=0.02) (Fig 1).

STEROID VARIABLES OF RETINAL VASCULITIS PATIENTS ON PREDNISOLONE $20 \mathrm{MG}$ /DAY

There were no significant differences between the SS and SR retinal vasculitis patients in any of the adrenocortical tests, or in plasma prednisolone levels.

\section{Discussion}

This study has shown that patients with idiopathic retinal vasculitis do not differ from controls in terms of cortisol and DHEA-S production, but that patients who are steroid resistant have a lower cortisol response to the SST and are more likely to have the ischaemic form of disease.

Steroid resistance in other inflammatory diseases is variably defined, and in retinal vasculitis there is no established definition. We used a cut off for relapse of $20 \mathrm{mg} /$ day because at this dose patients will experience significant side effects long term and a change to second line immunosuppression is indicated if this occurs more than once. We have referred to a patient's first occurrence so that subjects could not change groups as the longitudinal study progressed. Thus, the classification of SS and $\mathrm{SR}$ in this study is clinical, based on the response to treatment.

There is evidence for a defective HPA axis in autoimmune diseases. Patients with Cushing's disease can develop autoimmune thyroiditis and sarcoidosis after adrenalectomy ${ }^{16}{ }^{17}$ and patients with rheumatoid arthritis show a diminished cortisol response to surgical stress. ${ }^{5}$ This study has shown that retinal vasculitis patients have normal adrenocortical components of the HPA axis in terms of plasma cortisol levels, CSR, and DHEA-S, indicating that these are unlikely to be important in the pathogenesis of retinal vasculitis. However, only 30 subjects were recruited in this study, which limits its power.

We did not directly measure the hypothalamic response in the HPA axis because an insulin stress test purely for research purposes is considered unethical. Available evidence however suggests that the SST provides a safe means of determining overall HPA function. ${ }^{18}$ The cortisol rise in the SR patients was significantly diminished, indicating that SR patients could have a defective HPA axis.

The similarity between prednisolone clearance rates for SS and SR patients reflects results from previous studies. ${ }^{19}$ Adequate pred- 
nisolone levels when on $20 \mathrm{mg} /$ day were present in both SS and SR groups indicating that steroid resistance was not due to poor compliance.

Significantly more of the SR patients had the ischaemic form of the disease, which parallels our previous retrospective study. ${ }^{20}$ Whether ischaemic and non-ischaemic forms of retinal vasculitis represent different distinct clinical entities, or whether the ischaemic form merely represents a more severe form of the same disease remains arguable.

Steroid resistance in many inflammatory diseases poses a major therapeutic problem, and has been widely investigated. Despite this, a safe and reliable predictive test for steroid resistance remains elusive. With regard to $S R$ in retinal vasculitis, firstly, the ischaemic form of the disease is associated with resistance and, secondly, steroid resistance may be a function of a defective hypothalamic-pituitary-adrenal axis.

This research was funded by the St Thomas's Hospital endowments committee and the Iris Fund for the Prevention of Blindness.

1 Sanders MD. Duke Elder Lecture. Retinal arteritis, retinal vasculitis and autoimmune retinal vasculitis Eye 1987;1:441-65

2 Lightman S. Use of steroids and immunosuppressive drugs in the management of posterior uveitis. Eye 1991;5:294-8.

3 Howe L, Stanford MR, Edelsten C, et al. The efficacy of systemic steroids in sight threatening retinal vasculitis. Eye 1994;8:443-7.

4 McCulloch J, Lydyard PM, Rook GAW. Rheumatoid arthritis: how well do the theories fit the evidence? Clin Exp Immunol 1993;92:1-6.

5 Chikanza IC, Petrou P, Kingsley G, et al. Defective hypothalamic response to immune and inflammatory stimuli in patients with rheumatoid arthritis. Arthritis Rheum 1989; 35:1281-8.

6 Sternberg EM, Hill JM, Chrousos GP, et al. Inflammatory mediator-induced HPA axis activation is defective in streptococcal cell wall arthritis-susceptible Lewis rats. Proc Natl Acad Sci 1989;86:2374-8.

7 Forrester JV. Uveitis: pathogenesis. Lancet 1991;338:1498501.

8 Barton K, Lightman S. T lymphocyte effector mechanisms in the retina in posterior uveitis. Eye 1994;8:60-5.

9 Lightman S, Chan C-C. Immune mechanisms in choroidoretinal inflammation in man. Eye 1990;4:345-53.

10 Pagliogianni F, Ahuja SS, Balow JP, et al. Novel mechanism for inhibition of human T cells by glucocorticoids. F Immunol 1993;151:4081-9.

11 Ramirez F, Fowell DJ, Puklavec M, et al. Glucocorticoids promote a Th2 cytokine response by CD4+ T cells in vitro. f Immunol 1996;156:2406-12

12 Suzuki T, Suzuki N, Daynes RA, et al. Dehydroepiandrosterone enhances IL2 production and cytotoxic effector function of human T cells. Clin Immunol Immunopathol 1991;61:202-11.

13 Blauer KL, Poth M, Rogers WM, et al. Dehydroepiandrosterone antagonizes the suppressive effects of dexamethasone on lymphocyte proliferation. Endocrinology 1991;129: 3174-9

14 Stanford MR, Graham EM, Kasp E, et al. A longitudinal study of clinical and immunological findings in 52 patients with relapsing retinal vasculitis. $\mathrm{Br} \mathcal{F}$ Ophthalmol 1988;72: 442-7.

15 Brooks RV, Dupre J, Gogate AN, et al. Appraisal of adrenocortical hyperfunction; patients with Cushing's syndrome or 'non-endocrine' tumours. F Clin Endocrinol Metab 1963; 23:725-36.

16 Takasu N, Komiya I, Nagasawa Y, et al. Exacerbation of autoimmune thyroid dysfunction after unilateral adrenalectomy in patients with Cushing's syndrome due to an adrenocortical adenoma. N Engl F Med 1990;322:1708-12.

17 Steuer A, Cavan DA, Lowy C. Sarcoidosis presenting after resection of an adrenocortical adenoma. BMF 1995;310: $567-8$.

18 Stewart PM, Corrie J, Seckl JR, et al. A rational approach for assessing the hypothalamo-pituitary-adrenal axis. Lancet 1988;1:1208-10.

19 Lane SJ, Palmer JBD, Skidmore IF, et al. Corticosteroid pharmacokinetics in asthma. Lancet 1990;336:126S.

20 Palmer HE, Stanford MR, Sanders MD, et al. Visual outcome of patients with ischaemic and non-ischaemic retinal vasculitis. Eye 1996;10:343-8. 